\title{
Central flow tilting disc valve for aortic valve replacement
}

\author{
VIK ING OL O V B J̈ R K
}

The Thoracic Surgical Clinic, Karolinska Sjukhuset, Stockholm, Sweden

\begin{abstract}
A new central flow tilting disc valve has been introduced. The clinical experience from the first 50 patients treated with aortic valve replacement and followed up for 12 months is reported. The results obtained are so encouraging that the tilting disc valve is at present preferred for all aortic valve replacements in this institution.
\end{abstract}

The single most important feature of an artificial valve is a low gradient. This means fewer areas of stasis, less turbulence and stenosis with less cell damage, haemolysis, and thromboembolic complications.

Furthermore, high gradients with excessive turbulence may produce endocardial fibroelastosis and intimal sclerosis of the aortic root.

Theoretically, a valve which does not have a central occluder will give a better performance than one which has. Therefore, my efforts have been concentrated on the evaluation of a central flow tilting disc design for aortic valve replacement (manufactured by Shiley Laboratories, Inc.).

\section{EARLIER EXPERIENCE}

In a series of 120 patients treated with a StarrEdwards aortic ball valve prosthesis, 46 were recatheterized, showing a mean peak systolic gradient of $17.5 \mathrm{~mm} . \mathrm{Hg}$ at rest $^{1}$ and $41 \mathrm{~mm} . \mathrm{Hg}$ at work ${ }^{2}$ (Rodriguez, L., personal communication). The highest resting gradient in a patient receiving a No. 8A Starr-Edwards prosthesis was $70 \mathrm{~mm}$. $\mathrm{Hg}$, and of eight such cases only two are longterm survivors with resting gradients of 47 and $37 \mathrm{~mm}$. $\mathrm{Hg}$ respectively. In a narrow and calcific aortic root too little clearance between the ball and the sinus ridge was obtained, resulting in too high a gradient (Fig. 1).

The low profile Kay-Shiley disc valve permitted a better clearance between the disc and the aortic wall in patients with extensive subvalvular calcifications and big sinus ridges and was used in 88 aortic valve replacements (Fig. 2). The mean peak systolic gradient at rest was $27 \mathrm{~mm}$. $\mathrm{Hg}$ in 31 cases

${ }^{1}$ Average valve opening area $2.12 \mathrm{~cm} .^{2}$

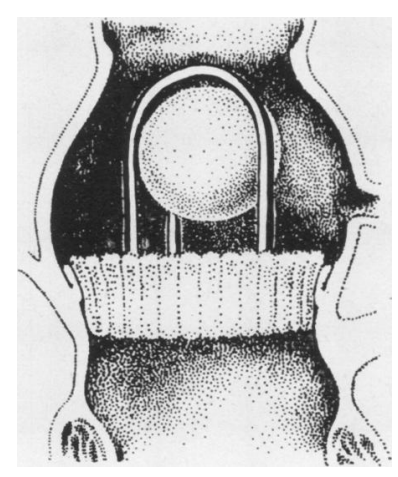

FIG. 1. A small clearance between the ball and the sinus ridge in systole, resulting in too high a gradient.

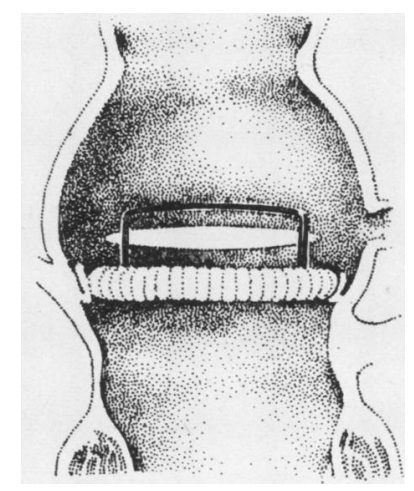

FIG. 2. The disc in its open position is, more often than $a$ ball, centred in the section of greatest flow area and therefore has a lesser gradient at the increased flow during exercise. 
(average valve opening $2.15 \mathrm{~cm} .^{2}$ ) and during exercise $38 \mathrm{~mm}$. $\mathrm{Hg}$. The result in patients with severe subvalvular calcification improved as a larger disc valve could be introduced than the ball valve, which had to be introduced into the left ventricle ( 26 cases with a cardiac work load of $400 \mathrm{kpm}$. $/ \mathrm{min}$. with an average valve opening of $2.23 \mathrm{~cm} .^{2}$, Ohlin, Ch., and Åström, H., personal communication). This was advantageous during exercise and attacks of tachycardia. The disc in

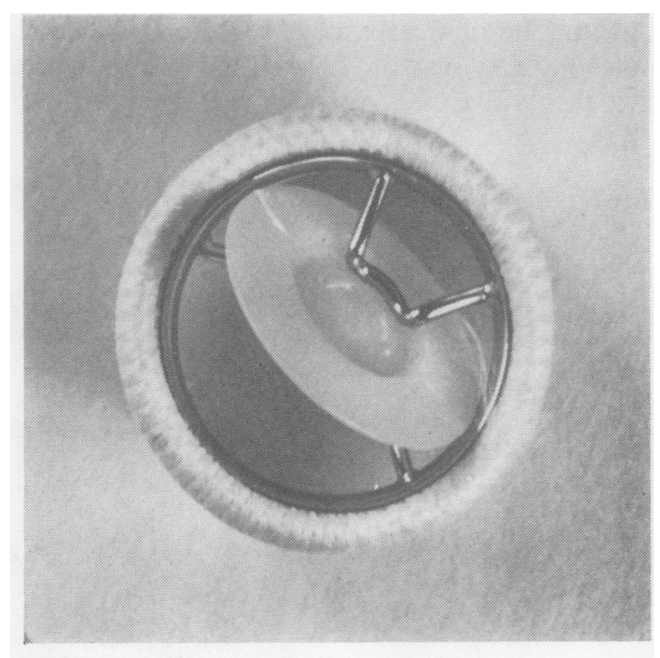

(a)

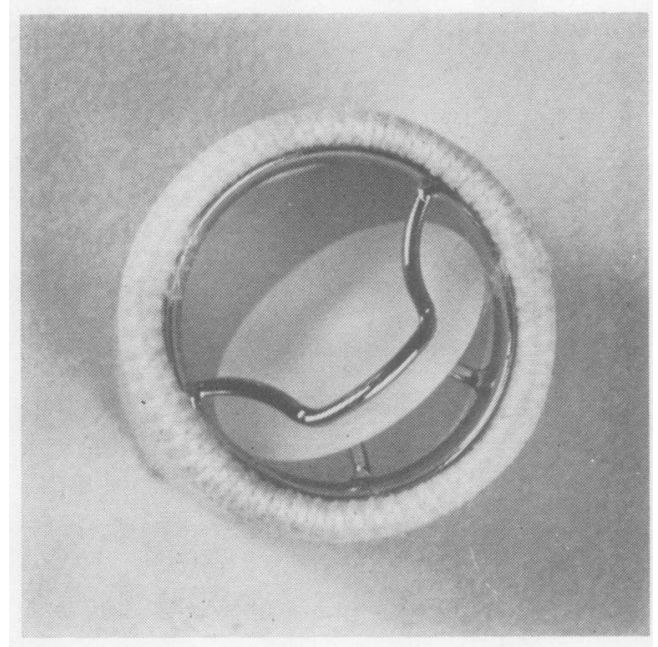

(b)

FIG. 3. The tilting disc valve in an open position viewed from (a) the outflow or aortic side, and (b) the inflow or left ventricular side. its open position is more often than a ball centred in the section of greatest flow area in the sinus of Valsalva and therefore has a lesser gradient at the increased flow during exercise.

The Wada-Cutter valve, which had approximately half the resting gradient in 11 cases as compared with the Kay-Shiley disc valve, clearly showed the haemodynamic advantage of a central flow. However, the hinge mechanism with a metal ridge stopper caused local compression in the Teflon disc with a disturbed balance of the valve and intermittent fixation of the disc in the open position in two cases combined with aneurysm of the ascending aorta and sinus of Valsalva. These advantages have been eliminated in a new central flow tilting disc design.

\section{THE CENTRAL FLOW TILTING DISC}

This aortic valve consists of a uniquely suspended free floating disc in a stellite cage (Fig. 3a and b). This valve has a suture ring of thin Tefion. Experimentally (Sawyer, Srinivasan, Lee, Martin,

(a)

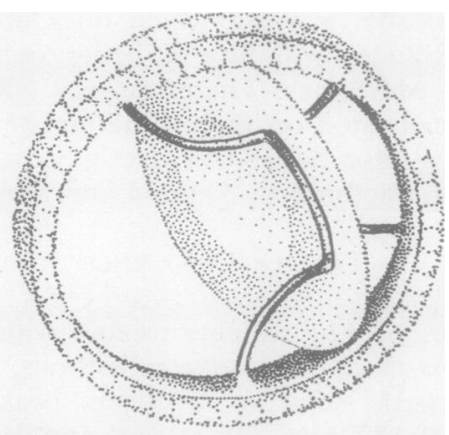

(b)

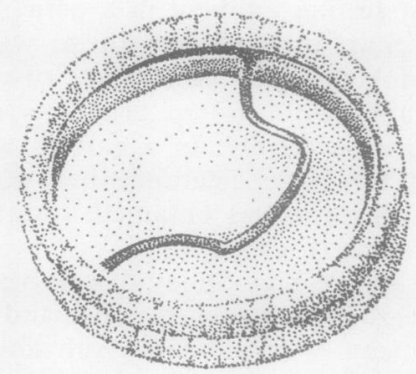

FIG. 4. The disc in the open (a) and closed (b) positions viewed from the inflow or left ventricular side, demonstrating the unique suspension of the free floating and rotating disc with its pivot point, shifting towards the centre as the disc closes. 
Murakami, and Stanczewski, 1969), stellite has displayed little tendency to oxidize, giving the best antithrombogenic results as its surface is more uniform electrically.

THE DISC In this design the free floating disc tilts about an imaginary hinge, providing central flow. The pivot point of the disc shifts towards the centre as the disc closes, greatly reducing closing impact velocity (Fig. $4 a$ and b). The extreme low mass inertia of the disc contributes to the effectiveness of the valve, especially at high pulse rates. The blood pressure has not dropped in patients with attacks of tachycardia and a pulse rate of $180 /$ minute. The disc is made of a thermoplastic material, (acetal resin) Delrin, which has the highest fatigue endurance limits and also the highest abrasion resistance of any commercial thermoplastic. Accelerated pulse duplicator tests show that projected wear limits will easily exceed 30 years.

The ratio of total orifice area to tissue diameter is significantly increased in this design. This feature, coupled with the central flow design, results in significantly lower gradients, a factor which is particularly important in patients with a narrow aortic root and calcific aortic stenosis.

As the disc does not overlap the ring but fits within the orifice area, the flow resistance is diminished as is the cardiac work load at the lower gradient. Blood trauma has been reduced to a minimum by the low gradient as well as by the fact that the disc does not hit the ring during diastole. Furthermore, less turbulence is encountered than in other valves.

The valve is available in the following sizes:

$\begin{array}{ccc}\begin{array}{c}\text { Size and } \\ \text { sewing } \\ \text { diameter } \\ (\mathrm{mm} .)\end{array} & \begin{array}{c}\text { Orifice } \\ \text { diameter } \\ (\mathrm{mm} .)\end{array} & \begin{array}{c}\text { Orifice } \\ \text { area } \\ (\mathrm{cm} .\end{array} \\ 19 & 14 & 1 \cdot 5 \\ 21 & 16 & 1.9 \\ 23 & 18 & 2 \cdot 5 \\ 25 & 20 & 3 \cdot 2 \\ 27 & 22 & 3 \cdot 7\end{array}$

OPERATIVE TECHNIQUE Through a median sternotomy the patient is connected to an AGA heartlung machine with disc oxygenator and automatic level control. Coronary perfusion and $30^{\circ} \mathrm{C}$. hypothermia is used. Care and time is taken to remove all calcium, piece by piece, after resection of the aortic cusps.

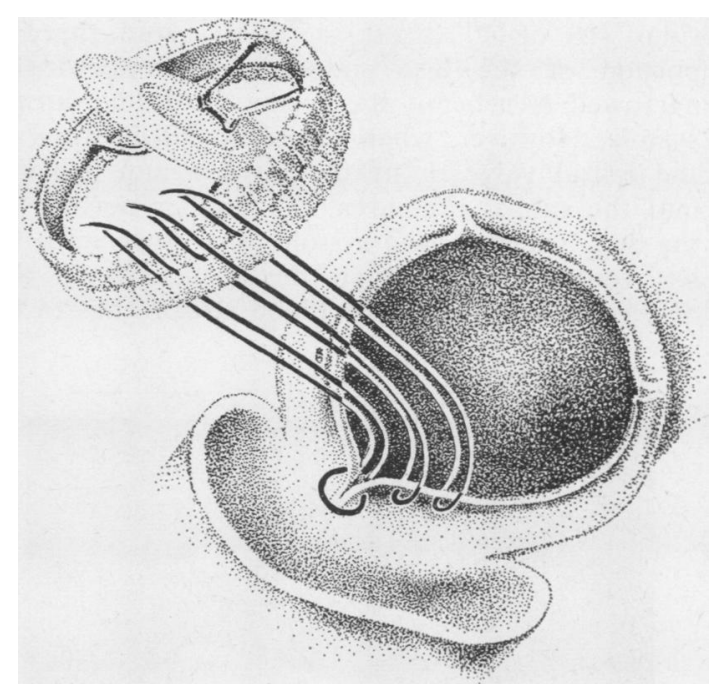

(a)

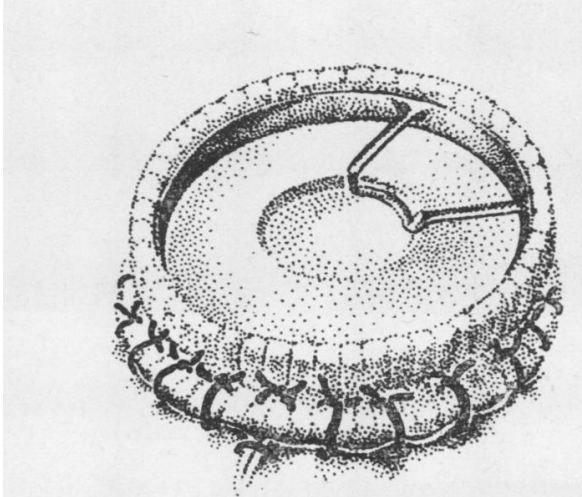

(b)

FIG. 5. (a) The suture technique with isolated sutures through the lower portion of the sewing cuff and horizontal mattress sutures in the commissures. (b) All sutures are tied below the upper rim of the prosthesis so that the cut end of the sutures cannot interfere with the free movements of the disc.

It is important not to choose too big a size of tilting disc valve prosthesis. All sutures should be placed in the lower portion of the suture ring, thereby ensuring that the knots can never interfere with the free motion of the disc. In a narrow aortic root isolated vertical sutures are used (Fig. $5 a$ and $b$ ).

Orientation of the disc does not influence the function as long as free movement is guaranteed. If the subvalvular area is free, the smaller portion 
of the disc is orientated towards the noncoronary sinus (18 of 40 cases) so as to avoid the big portion of the disc coming too close to the narrowed area below the aortic suture line during systole. However, when extensive calcification of the mitral valve or of the myocardium projects into the subvalvular area, the smaller portion of the disc, which during systole goes down into the left ventricle and permits the aortic side of the disc to be washed by the blood stream, has to be

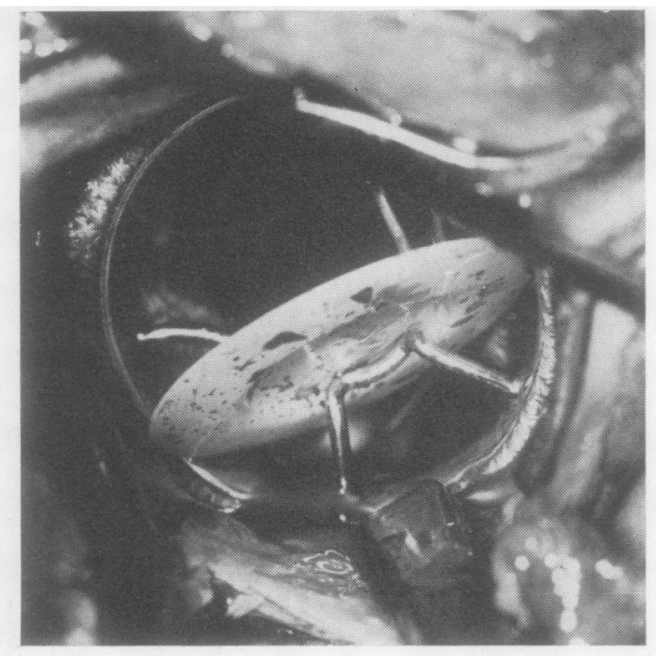

(a)

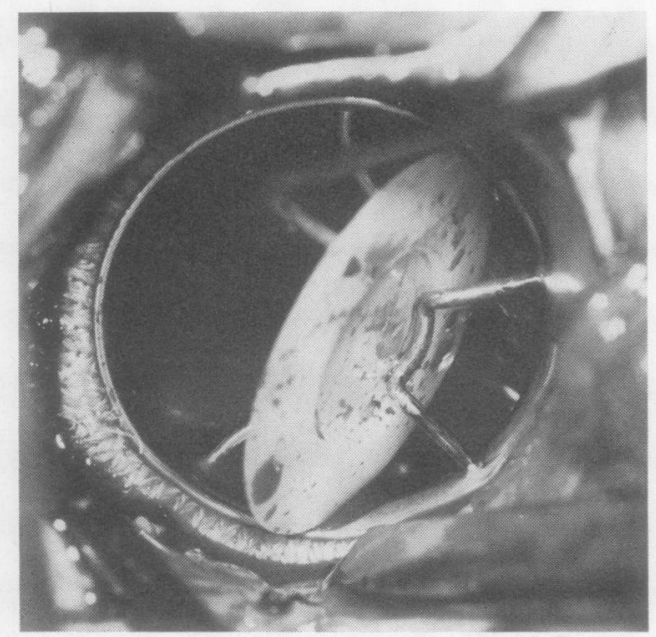

(b)



(c)

FIG. 6. Case 27. Photographs taken during operation showing how, after the sutures have been tied, the inner ring with the disc can be turned so that the downward moving portion of the disc is guaranteed free motion, $\bar{\partial}$ orientation towards the left aortic sinus (a) towards the noncoronary sinus $(b)$ in the open $(c)$ and in the closed position. This turning is made by a new hook for the forceps against the legs, taking care not to interfere with $\overline{0}$ the adjustment of the two legs.

orientated towards either the right (5 of 40 cases) or the left (6 of 40 cases) or very often towards $\underset{x}{\stackrel{2}{x}}$ the commissure between the left and right aortic $\dot{0}$ cusps (11 of 40 cases), as the case may be, in order 3 . to ensure free movement of the smaller portion $\delta$ of the disc. The proper orientation may be effected after the valve has been sutured in place by을 turning the inner ring, being careful not to inter- $D$ fere with the adjustment of the two legs (Fig. 6a-c). Anticoagulation treatment is started on the third post-operative day.

MATERIAL In the first 50 patients operated upon the age range was from 25 to 64 years.

There were 40 cases of calcific aortic stenosis and 10 of aortic insufficiency. Ten patients had $\Phi$ concomitant procedures: 1 patient had an + aneurysm of the ascending aorta (Marfan's syn- 0 drome) resected and grafted; 1 patient had $\mathrm{a}_{\mathbb{\mathrm { D }}}^{\circ}$ subvalvular obstructive cardiomyopathy resected; $\stackrel{\odot}{\oplus}$ and 1 patient had an additional valve of the same $\propto$ design in the mitral area and a tricuspid annulo- 0 plasty as well. The remaining 7 patients had a concomitant mitral commissurotomy. 
RESULTS

There were 6 deaths, 4 due to myocardial failure, $0,1,1$ and 2 months post-operatively, and 2 due to sepsis, 3 weeks and 2 months post-operatively.

Complications Two cases of embolism occurred in connection with the operation after removal of calcific aortic valves, resulting in hemiplegia. One patient is living and sitting in a wheelchair, the other died in myocardial failure, as a result of an unsuccessful concomitant mitral commissurotomy.

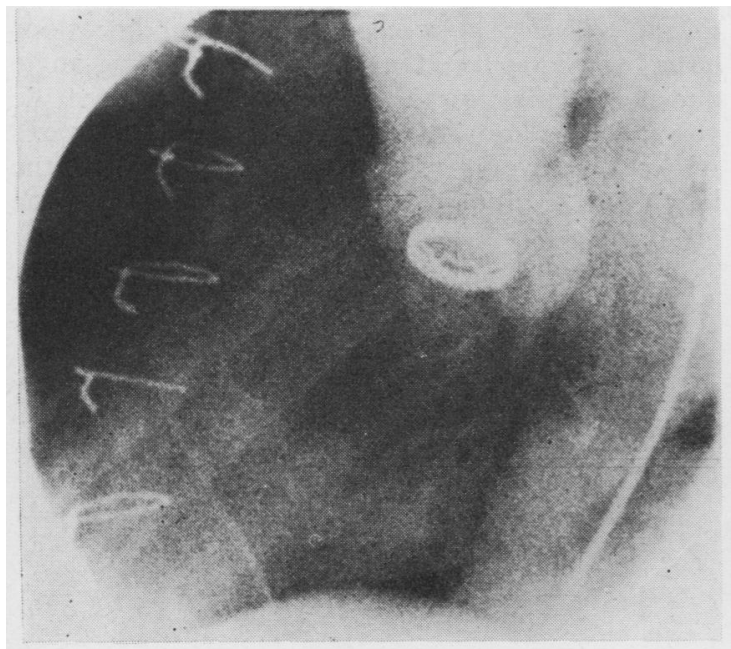

(a)



(b)

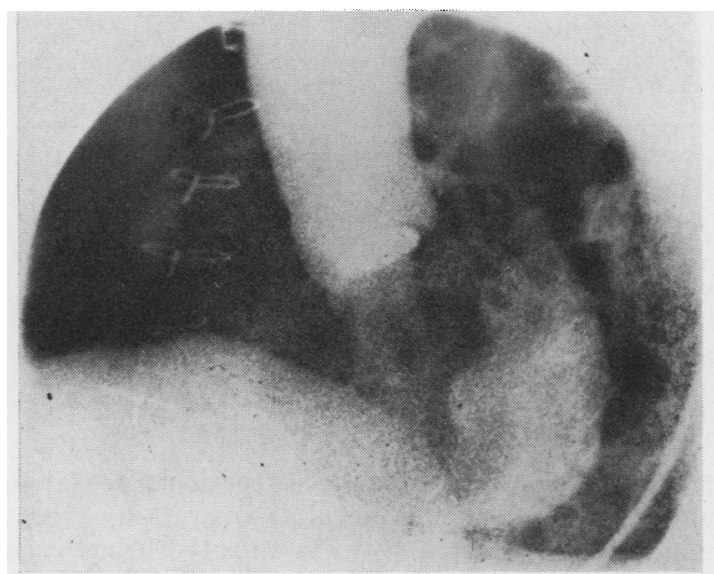

(c)

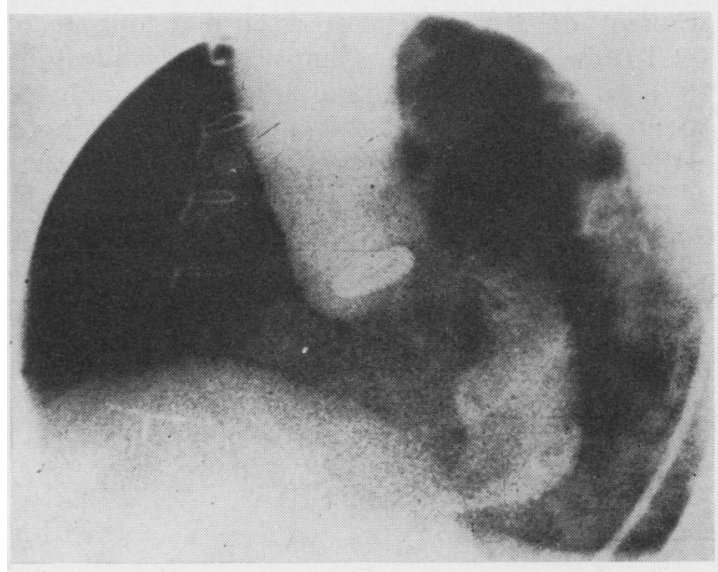

(d)

FIG. 7. Case 19. Cineangiography at follow-up 6 months after operation. (a) Right anterior oblique projection during diastole. Minimal subvalvular regurgitation visible. (b) Right anterior oblique projection during systole. (c) Left anterior oblique projection during diastole. Minimal subvalvular regurgitation visible. (d) Left anterior oblique projection during systole.

GRADIENT AT END OF OPERATION The mean systolic peak gradient at the end of the operation was $5.4 \mathrm{~mm}$. $\mathrm{Hg}$ (range 0-25). The mean systolic peak gradient was $11.7 \mathrm{~mm}$. $\mathrm{Hg}$ for the valve with a $21 \mathrm{~mm}$. tissue diameter, $4.4 \mathrm{~mm}$. $\mathrm{Hg}$ for the valve with a $23 \mathrm{~mm}$. tissue diameter, $5.4 \mathrm{~mm}$. $\mathrm{Hg}$ for the valve with a $25 \mathrm{~mm}$. tissue diameter, and only $3.0 \mathrm{~mm}$. $\mathrm{Hg}$ for the valve with a $27 \mathrm{~mm}$. tissue diameter (Table). 
T A B L E

GRADIENT OVER AORTIC VALVE CORRELATED WITH FLOW, MEASURED BY ELECTROMAGNETIC FLOWMETER DURING OPERATION

\begin{tabular}{|c|c|c|c|c|c|c|c|}
\hline $\begin{array}{c}\text { Size } \\
\text { of } \\
\text { Valve } \\
\text { (mm.) }\end{array}$ & $\begin{array}{c}\text { No. } \\
\text { of } \\
\text { Cases }\end{array}$ & $\begin{array}{l}\text { Mean } \\
\text { Systolic } \\
\text { Peak } \\
\text { Gradient } \\
\text { (mm. } \\
\text { Hg) }\end{array}$ & $\begin{array}{c}\text { Range } \\
\text { (mm. } \\
\mathbf{H g})\end{array}$ & $\begin{array}{l}\text { Mean } \\
\text { Cardiac } \\
\text { Output } \\
\text { (1./min.) }\end{array}$ & $\begin{array}{l}\text { Range } \\
(1 . / \mathrm{min} .)\end{array}$ & $\begin{array}{l}\text { Stroke } \\
\text { Volume } \\
\text { (ml.) }\end{array}$ & $\begin{array}{l}\text { Range } \\
\text { (ml.) }\end{array}$ \\
\hline $\begin{array}{l}21 \\
23 \\
25 \\
27\end{array}$ & $\begin{array}{r}7 \\
16 \\
16 \\
11\end{array}$ & $\begin{array}{r}11 \cdot 7 \\
4 \cdot 4 \\
5 \cdot 4 \\
3 \cdot 0\end{array}$ & $\begin{array}{l}1-25 \\
0-13 \\
0-14 \\
0-12\end{array}$ & $\begin{array}{l}6 \cdot 2 \\
4 \cdot 2 \\
5 \cdot 1 \\
5 \cdot 2\end{array}$ & $\begin{array}{l}3 \cdot 8-10 \\
2 \cdot 7-7 \\
3 \cdot 4-7 \cdot 7 \\
3 \cdot 2-6 \cdot 7\end{array}$ & $\begin{array}{l}74 \\
68 \\
64 \\
72\end{array}$ & $\begin{array}{l}55-125 \\
31-130 \\
34-115 \\
51-105\end{array}$ \\
\hline
\end{tabular}

Follow-uP The remaining 44 patients are alive and well 4 to 12 months after operation, except one with hemiplegia, who is mostly sitting in a wheel chair but can walk with two sticks. Seven patients were followed for more than one year. The patient with the longest follow-up was recatheterized after 8 months and showed a resting gradient of $2 \mathrm{~mm}$. $\mathrm{Hg}$ at a cardiac output of $4.2 \mathrm{l} . / \mathrm{min}$. and stroke volume of $64 \mathrm{ml}$. with a $25 \mathrm{~mm}$. size valve. The gradient rose only to $10 \mathrm{~mm}$. at a work of $200 \mathrm{kpm} . / \mathrm{min}$., giving a cardiac output of $7 \cdot 1 \mathrm{1} / \mathrm{min}$. and a stroke volume of $84 \mathrm{ml}$. The heart had diminished in size, the maximal working capacity was $600 \mathrm{kpm} . / \mathrm{min}$. and there was no regurgitation clinically or by aortography. The red blood cell destruction was less than is usually observed in aortic valve replace- $\overrightarrow{\vec{c}}$ ment, as judged by a normal haptoglobin value of $45 \mathrm{mg} . \%$ compared to the average value of $18.7 \mathrm{mg} . \%$ using a Starr-Edwards ball valve, and $\frac{\text { क }}{2}$ $20 \mathrm{mg}$. \% using a Kay-Shiley disc valve

\section{DISCUSSION}

Although the clinical experience with the new $\overrightarrow{\vec{\omega}}$ tilting disc valve at present covers a follow-upo period of up to only one year, the low gradients obtained and the clinical results achieved are encouraging. For aortic valve replacement the valve described is now the one preferred. For ${ }_{-}^{+}$ mitral valve replacement certain modifications have been introduced regarding the opening angleo and the sewing ring to facilitate application of the valve in the mitral area. The principle remainse the same, however. The central flow design of the new valve is thought to be a most significant step $\vec{\oplus}$ forward in the development of artificial valves.

To date 95 cases of aortic valve replacement and 28 mitral valve replacements have been performed with the tilting disc valve prosthesis.

\section{REFERENCE}

Sawyer, P. N., Srinivasan, S., Lee, M. E., Martin, J. G., Murakami, T., and Stanczewski, B. (1969). The influence of the metal interface charge on long-term function of prosthetic heart valves. In Prosthetic Heart Valves, pp. 198-219. Thomas, Springfield. 